\title{
TRANSIÇÃO PARA O ENSINO SECUNDÁRIO EM PORTUGAL: VOZES DE ESTUDANTES SOBRE DIFICULDADES ACADÊMICAS*
}

\author{
Ana Cristina Torres ${ }^{1}$ (D) \\ Ana Mouraz ${ }^{1}$ (1)
}

\begin{abstract}
RESUMO: O artigo apresenta e discute perspetivas de estudantes recém-chegados ao ensino secundário sobre as principais dificuldades acadêmicas que referem ter sentido na transição para esta última etapa obrigatória da escolaridade em Portugal, relacionando-as com a organização curricular das modalidades dos seus cursos. De acordo com as perspetivas recolhidas em seis grupos de discussão focalizada, esta transição parece configurar-se de sentimentos mais positivos para estudantes em cursos profissionais do que para estudantes em cursos científico-humanísticos. Os primeiros apenas referem ter de adaptar-se à elevada carga horária dos cursos. Os segundos lutam com a rapidez e exigência do ensino e do trabalho autônomo resultantes da pressão dos programas e exames. Estes resultados suportam a necessidade de se conceder maior flexibilidade e abertura à organização curricular do ensino secundário.
\end{abstract}

Palavras-chave: Transição de estudantes. Ensino secundário. Vozes de estudantes. Dificuldades académicas.

\section{TRANSITION TO UPPER SECONDARY EDUCATION IN PORTUGAL: STUdENTS' VOICES ABOUT ACADEMIC DIFFICULTIES}

ABSTRACT: This article presents and discusses the perspectives of newcomer upper secondary school students about academic difficulties they mention to have experienced in the transition to this last compulsory stage of schooling in Portugal, relating them with the curriculum structure of their courses' modalities. According to the perspectives gathered in six focus group discussions, this transition seems to bring

\footnotetext{
*Artigo derivado do projeto "Transiçôes de estudantes - vozes de estudantes sobre o currículo e o trabalho curricular nas escolas em dois sistemas educativos" financiado pela Fundação para a Ciência e a Tecnologia (SFRH/BPD/108950/2015) no âmbito do Programa Operacional Capital Humano, comparticipado pelo Fundo Social Europeu e por fundos nacionais do Ministério da Ciência, Tecnologia e Ensino Superior (MCTES) de Portugal e apoiado pelo projeto estratégico do Centro de Investigação e Intervenção Educativas da Faculdade de Psicologia e de Ciências da Educação da Universidade do Porto (Portugal).

${ }^{1}$ Universidade do Porto, Faculdade de Psicologia e Ciências da Educação, Centro de Investigação e Intervenção Educativas - Porto, Portugal. E-mails: acctorres@fpce.up.pt; anamouraz@fpcc.up.pt DOI: 10.1590/ES0101-73302019186268
} 
more positive feelings to students in vocational courses than to those in general academic courses. The former only state to have to adapt to the busy weekly schedules of their courses. The latter struggle with the teaching speed and high demand for autonomous work as a result from the pressure of syllabuses and exams. These findings support the need to invest in the curricular organization of upper secondary education with greater flexibility and openness.

Keywords: Students' transitions. Upper secondary school. Student voices. Difficulties.

\section{Transición PARA la ENSEÑANZa SECUNDARIA EN PoRTUgal: VOCES DE ESTUDIANTES SOBRE DIFICULTADES ACADÉMICAS}

RESUMEN: El artículo presenta y discute perspectivas de estudiantes recién llegados a la enseñanza secundaria sobre las principales dificultades académicas que refieren haber sentido en la transición para esta última etapa obligatoria de la escolaridad en Portugal, relacionándolas con la organización curricular de las modalidades de sus cursos. De acuerdo con las perspectivas recogidas en seis grupos de discusión focalizada, esta transición parece configurarse de sentimientos más positivos para estudiantes en cursos profesionales de que para estudiantes en cursos científico-humanísticos. Los primeros apenas refieren tener que adaptarse a la elevada carga horaria de los cursos. Los segundos luchan con la rapidez y exigencia de la enseńanza y del trabajo autónomo resultantes de la presión de los programas y exámenes. Estos resultados soportan la necesidad de conceder mayor flexibilidad y apertura a la organización curricular de la enseñanza secundaria.

Palabras clave: Transición de estudiantes. Enseñanza secundaria. Voces de estudiantes. Dificultades académicas.

\section{Introdução}

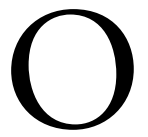

ensino secundário, em Portugal, inicia no $10^{\circ}$ ano de escolaridade, abrange alunos entre 15 e 18 anos de idade, correspondendo ao ensino médio no Brasil e ao que na literatura internacional se identifica como upper secondary education (europeia) ou high school (anglo-saxónica). No país, a atenção à transição para esse ciclo de escolaridade ganhou importância pelo recente alargamento da escolaridade obrigatória até aos 18 anos, no sentido de promover a qualificação da população e prevenir o abandono escolar precoce (ARAÚJO et al., 2014). Com esse alargamento, promoveu-se ainda a expansão das vias profissionais de ensino secundário e pós-secundário. As escolas com oferta de ensino secundário 
passaram recentemente a acolher tanto estudantes com aspiraçóes a uma qualificação mais elevada, como aqueles que, até há pouco tempo, esperavam estar apenas nove anos na escola. As tensōes desse ensino secundário diversificado (MATOS, 2013) colocam as escolas e os jovens diante de tantos novos desafios como novas oportunidades de mudança. Por um lado, a oferta formativa tem sido diversificada para responder a requisitos do mercado laboral, do acesso ao ensino superior e das expectativas dos jovens. Por outro, os jovens vêm-se obrigados a efetuar escolhas vocacionais na entrada do ensino secundário, as quais, para muitos, surgem demasiado cedo e desfasadas das suas temporalidades de desenvolvimento individual (VIEIRA; PAPPÁMIKAIL NUNES, 2012). Tais desafios complexificam-se em um sistema educativo que ainda não resolveu problemas de reduzidas flexibilidade curricular e articulação curricular entre formaçóes e ciclos de estudos (FERNANDES, 2006), arriscando à formação de guetos nas escolas (AZEVEDO, 2007). Acresce que o histórico fosso curricular entre as exigências do ensino básico e as do ensino secundário (GARRIDO, 1999) frequentemente condiciona experiências escolares problemáticas entre jovens no ensino secundário, sobretudo na fase inicial de adaptação ao novo contexto (TEIXEIRA \& FLORES, 2010). Contudo, a atenção às dificuldades experienciadas pelos estudantes nessa fase de transição é ainda escassa (GONÇALVES; NIEMIVIRTA; LEMOS, 2017; LOPES, 2005; TORRES \& MOURAZ, 2015).

Nesse contexto, desenvolveu-se um estudo qualitativo das dificuldades acadêmicas experienciadas por estudantes na entrada do ensino secundário em Portugal, procurando relacioná-las com as modalidades de cursos que frequentam. Nesse texto, após o enquadramento teórico-metodológico inicial, apresentou-se e discutiu-se os discursos de estudantes de cursos científico-humanísticos e profissionais sobre as dificuldades acadêmicas sentidas na entrada do ensino secundário, terminando com algumas reflexóes sobre a importância de repensar o currículo do ensino secundário em Portugal para ajustá-lo aos novos perfis de estudantes que enfrentam a escolaridade obrigatória alargada em tempos de renovados desafios colocados à escola e à sociedade.

\section{Dificuldades na transição de estudantes para o ensino secundário: entre um quadro internacional e as especificidades nacionais}

Não raras vezes, na entrada do ensino secundário degradam-se abruptamente os resultados acadêmicos (ANDERSON et al., 2000; OTES, 2015) como consequência do acumular de problemas em ciclos anteriores (AZEVEDO, 2007) e com a tendência para a desafetação e abandono escolares durante a frequência desse ciclo (ARAÚJO et al., 2014). Em Portugal, mais de um terço dos alunos que chega ao ensino secundário já tem pelo menos uma retenção no seu trajeto e perto 
de $10 \%$ sofre uma retenção nesse ciclo de escolaridade, um problema que atravessa cursos científico-humanísticos e profissionalizantes (PORTUGAL, 2016a). A transição para o ensino secundário é uma etapa de incerteza a instabilidade na vida dos estudantes, agravada por acontecer em uma idade de fortes alteraçóes psicossociais e físicas. Por isso, há quem atente para questôes do desenvolvimento adolescente (DISETH \& SAMDAL, 2014; GONÇALVES; NIEMIVIRTA; LEMOS, 2017) e há quem olhe para os contextos socioculturais (BENNER, 2011) nos quais a transição ocorre. No que concerne a esses últimos, tem sido reportada a ocorrência de dificuldades de natureza acadêmica/curricular, organizacional/processual ou social (AKOS \& GALASSI, 2004; ANDERSON et al., 2000; LOPES, 2005; TORRES \& MOURAZ, 2015). Em vários sistemas educativos, a mudança não só de ciclo, mas também de escola, reveste essa transição de dificuldades particularmente de natureza psicossocial (AKOS \& GALASSI, 2004; ANDERSON et al., 2000; BENNER, 2011; PEREIRA \& POOLEY, 2007). Contudo, em Portugal, a oferta do último ciclo do ensino básico e do ensino secundário na maioria das escolas secundárias, além do agrupamento de estabelecimentos de ensino próximos evita, muitas vezes, a necessidade de mudança de escola ou ajuda para que os jovens mudem de escola com os seus grupos de pares.

Por partir do ponto de vista de uma análise curricular, o estudo que aqui se reporta debruçou-se sobre as dificuldades de natureza acadêmica que os jovens reportam durante a transição, isto é, aquelas que se referem à estrutura, conteúdos e tipo de trabalho dos seus cursos e disciplinas (AKOS \& GALASSI, 2004; TORRES \& MOURAZ, 2015). Efetivamente, o estudo de Torres e Mouraz (2015) sugeriu serem as dificuldades acadêmicas aquelas que mais marcam os estudantes portugueses na entrada do ensino secundário. Tais dificuldades iniciam na especialização disciplinar de que esse ciclo de escolaridade se reveste, que traz consigo novas relações com colegas e professores, maiores responsabilidades, exigências e expectativas de trabalho (BENNER, 2011), além de aspiraçóes mais específicas de qualificações e vias de futuro. Chegam, também, novos horários, novas metodologias de ensino e currículos transbordados de conteúdos (NÓVOA, 2009), cuja aprendizagem por parte dos estudantes, mais tarde ou mais cedo, será sujeita à examinação, o que tem estado frequentemente na raiz de visóes negativas que os estudantes têm da escola e da educação (TEIXEIRA \& FLORES, 2010). Daí, as novas exigências dos conteúdos, trabalho autônomo e avaliação constarem entre as dificuldades que os estudantes mais referem sentir após a entrada no ensino secundário (AKOS \& GALASSI, 2004; DARMODY, 2008; PEREIRA \& POOLEY, 2007; TORRES \& MOURAZ, 2015). É, também, usual, os estudantes perceberem menor monitorização e apoio por parte dos professores (BENNER, 2011; DE WIT; KARIOJA; RYE, 2010; PEREIRA \& POOLEY, 2007), uma vez que são chamados a serem mais autônomos e responsáveis nas tarefas de aprendizagem. Tais perceçóes têm sido mais marcantes em estudantes em percursos acadêmicos, porquanto esses reportam sentir mais pressão no seu trabalho e resultados 
(PEREIRA \& POOLEY, 2007), em grande parte condicionados pelos requisitos de acesso ao ensino superior.

Como consequência, alguns desses estudantes acabam por sentir-se insatisfeitos com os ambientes de turma e com o esforço dos professores em tornarem as aulas mais interessantes (OTES, 2015), em uma tendência mais marcada em estudantes de cursos científico-humanísticos (acadêmicos). Já estudantes em cursos profissionais tendem a reconhecer maior esforço nos seus professores em acompanhar os alunos com dificuldades e a reconhecer mais interligaçóes entre matérias estudadas nas diferentes disciplinas (OTES, 2015), o que parece estar na base de experiências de transição menos problemáticas. Com efeito, em uma escuta de vozes de alunos do ensino secundário sobre o currículo, esses reconheceram problemas de sobrevalorização dos testes, da diminuição da importância da relação professor-aluno, da excessiva carga horária e, por fim, de rigidez nas disciplinas dos cursos (PORTUGAL, 2016b). A reduzida flexibilidade entre as modalidades de cursos existentes em Portugal — científico-humanísticos, artísticos ou profissionais — será também uma condicionante da boa integração dos estudantes no ensino secundário. $\mathrm{O}$ poder de escolha dos estudantes termina, na maioria das vezes, na escolha do curso, porquanto estão impedidos, por exemplo, de trocar algumas disciplinas ou misturar áreas de formação para frequentar disciplinas para as quais estão mais motivados ou que lhes abrem portas a alternativas mais diversas de trajetos escolares e profissionais. ${ }^{1}$

Os cursos atuais, com planos de estudos predeterminados para três anos, onde a escolha de disciplinas é reduzida ou inexistente, gera tensóes entre a oferta formativa das escolas e as expectativas e aspiraçóes dos estudantes e pode estar na origem de frustrações e insucessos ao longo do ensino secundário. Por essas razóes, tem sido apontada a necessidade de se desenvolver um melhor trabalho de informação e orientação que de fato esclareça melhor os estudantes acerca dos futuros cursos, das suas exigências e do seu funcionamento (FERNANDES, 2006; ALCOFORADO et al., 2014), bem como um reforço da sua independência e autonomia previamente à transição (DISETH \& SAMDAL, 2014; TORRES \& MOURAZ, 2015).

\section{Objetivos e metodologias}

Este estudo exploratório procurou recolher perspetivas de estudantes na entrada do ensino secundário, com os objetivos de descrever as principais dificuldades acadêmicas que os estudantes referem sentir na transição para o ensino secundário; e relacionar as dificuldades emergentes dos discursos de estudantes com as modalidades de cursos que frequentam: científico-humanísticos ou profissionais. Isso porque, para além da reduzida atenção a essa problemática, do ponto de vista curricular, no contexto português (TORRES \& MOURAZ, 2015) são escassos os estudos que procuram captar as perceçóes dos estudantes nessa fase a partir dos seus próprios discursos (AKOS \& GALASSI, 2004; PEREIRA \& POOLEY, 2007). 
Embora o reconhecimento da validade e riqueza da escuta de estudantes sobre questôes curriculares e pedagógicas encontre ainda várias resistências políticas e organizacionais (ex. ARNOT \& REAY, 2007; LUNDY \& COOK-SATHER, 2016), várias vantagens dessas práticas têm sido avançadas para o desenho e implementaçáo de currículos mais contextualizados, desafiadores e coerentes com os interesses e experiências dos estudantes (JENKINS, 2006; OSBORNE \& COLLINS, 2001). Privilegiou-se a metodologia de grupo de discussão focalizada, concordando-se com Osborne e Collins (2001) na ideia de que tal metodologia permitiria recolher um conjunto mais diversificado de perspetivas em um ambiente aberto, suportado por pares e mitigador de sentimentos de coaçáo à resposta. Embora uma investigação anterior sugira que a saturação de dados aconteça após três a quatro grupos (VAUGHAN; SCHUMM; SIAGUH, 1996), conduziu-se um total de seis grupos de discussão em duas escolas profissionais e duas escolas secundárias da regiâo norte do país entre janeiro e maio de 2016. Sem quaisquer ambições a uma generalização de dados, o conjunto de escolas participantes procurou, contudo, captar diferenças de organização escolar (secundária versus profissional) e territoriais de oferta formativa, com a inclusão do contraste entre contexto fortemente urbano e contexto maioritariamente rural.

Em cada escola, organizaram-se grupos de cerca de seis a oito estudantes e, seguindo investigação anterior (KRUEGER \& CASEY, 2000), solicitou-se a homogeneização dos grupos de acordo com a modalidade de curso: científico-humanístico ou profissional. Para isso, em cada uma das escolas secundárias dinamizou-se dois grupos de discussão. Os estudantes foram selecionados aleatoriamente na base de um a dois por curso/turma na escola e previamente convidados pela direção de cada escola a participar nos grupos, tendo apenas participado após aceitação, leitura e assinatura de um termo de consentimento informado, juntamente com seus encarregados de educação. Nas escolas em contextos menos urbanos, o número de participantes foi menor por se incluir apenas um aluno de cada turma de $10^{\circ}$ ano. A distribuiçáo dos participantes nos grupos dinamizados encontra-se sintetizada na Tabela 1 . Desses estudantes, 17 tinham 15 anos de idade e os restantes tinham entre 16 e 19 anos de idade. À exceção de três, todos os estudantes estavam pelo primeiro ano nas escolas que frequentavam.

Nas sessóes, os estudantes foram desafiados a falar sobre as dificuldades de integração que experienciaram no ensino secundário, com foco nas particularidades dos seus cursos que foram percebidas como especialmente diferentes das do ensino básico e causadoras de dificuldades. Os grupos de discussão foram conduzidos pelas investigadoras autoras do estudo e sempre assistidos em observação e anotação por um/a segundo/a investigador/a.

As perspetivas recolhidas nos grupos de discussão foram sujeitas a uma análise de conteúdo (BARDIN, 2000) de natureza exploratória e interpretativa, na qual se procurou salientar os discursos dos estudantes. 


\section{Dificuldades acadêmicas nas vozes de estudantes em cursos científico-humanísticos}

Nos estudantes, a referência à necessidade de lidar com o aumento do volume e rapidez de ensino dos conteúdos programáticos foi a mais consensual como principal dificuldade sentida na transição, em parte aliada à perceção de um acrescido rigor e volume do trabalho autônomo solicitado e de maior exigência nos procedimentos de avaliaçáo, já reportadas em outros estudos (AKOS \& GALASSI, 2004; DARMODY, 2008; PEREIRA \& POOLEY, 2007) e no contexto português (PORTUGAL, 2016b; TORRES \& MOURAZ, 2015).

No que concerne ao ritmo de ensino dos conteúdos e seu volume, estudantes dos dois grupos especificaram que "era muito rápido" (1C), que "há demasiada informação" (2B), que "os stôres [sic] se estấo demasiado a focar no "que se tem que dar" (2D) e que "nunca pensei que numa só semana desse tanta matéria" (1B). Para uma estudante que tinha mudado de um curso científico-humanístico para um curso profissional da mesma escola, durante o $1^{\circ}$ período letivo:

eu senti dificuldades [...] no facto de os professores serem muito rápidos e vagos a explicarem a matéria e, a matéria é explicada num dia, e noutro dia a matéria já é outra. E temos que perceber a matéria no próprio dia. Se não percebemos a matéria do dia anterior, já não percebemos mais nada para a frente. E é muito complicado, porque eu sei que me custa apanhar a matéria $(2 \mathrm{H})$.

\section{Tabela 1}

Distribuição de participantes nos grupos de discussão.

\begin{tabular}{|c|c|c|c|c|c|}
\hline & Escola & Gênero & $\begin{array}{c}\text { Cursos científico- } \\
\text { humanísticos }\end{array}$ & $\begin{array}{c}\text { Cursos } \\
\text { profissionais }\end{array}$ & \\
\hline \multirow{4}{*}{$\begin{array}{l}\text { Escolas } \\
\text { secundárias }\end{array}$} & \multirow{2}{*}{ Escola A } & $\mathrm{F}$ & 4 & 2 & 6 \\
\hline & & M & 3 & 3 & 6 \\
\hline & \multirow{2}{*}{ Escola B } & $\mathrm{F}$ & 2 & & 2 \\
\hline & & M & 3 & 3 & 3 \\
\hline \multirow{7}{*}{$\begin{array}{l}\text { Escolas } \\
\text { profissionais }\end{array}$} & \multirow{2}{*}{ Escola C } & $\mathrm{F}$ & & 6 & 6 \\
\hline & & M & & 1 & 1 \\
\hline & \multirow{2}{*}{ Escola D } & $\mathrm{F}$ & & 1 & 1 \\
\hline & & $\mathrm{M}$ & & 4 & 4 \\
\hline & & $\mathrm{F}$ & 6 & 8 & 15 \\
\hline & & M & 6 & 11 & 17 \\
\hline & & & 12 & 20 & 32 \\
\hline
\end{tabular}

F: feminino; M: masculino. 
Efetivamente, como essa estudante, 5\% de estudantes de cursos científico-humanísticos tende a mudar de curso durante o $10^{\circ}$ ano (dados de 2013-2014), sendo a dificuldade ou a obtenção de maus resultados algumas das principais razóes apontadas para isso (OTES, 2015). A mudança ocorre no $10^{\circ}$ ano porque é o ano onde os estudantes menos perdem ao redirecionar o seu percurso escolar, circunstância que, tal como já criticada por outros estudantes (PORTUGAL, 2016b), aponta para a ineficácia da reduzida permeabilidade entre cursos no sistema.

Como consequência surge o sentimento da "pressão que é feita nos alunos $[\ldots]$ que é, temos que ver isto agora, e tudo muito rápido" (2B), especialmente quando "as stôras [sic] estão sempre a dizer que há muita matéria e que temos de estudar" (2A). Sentimentos de pressão são frequentes em estudantes que ingressam percursos mais acadêmicos (PEREIRA \& POOLEY, 2007) e estão normalmente associados a requisitos de avaliaçôes internas e externas, além da necessidade de uma maior independência e autonomia no estudo (AKOS \& GALASSI, 2004; DARMODY, 2008), como antes reportado no contexto português (TORRES \& MOURAZ, 2015). Como explica uma estudante "o que é certo é que o meu ritmo de estudo do ano passado não chega para agora, o que me fez sentir um pouco mais de pressáo" (1A).

Por outro lado, apesar de reconhecerem o ritmo de ensino e a exigência do trabalho autônomo como principais causas da pressáo, os estudantes entendem que os próprios professores se sentem, eles mesmos, pressionados pelos "programas e manuais" (2B), e que "a culpa nem é deles" (2D). Encaram com naturalidade o aumento do volume de conteúdos em algumas disciplinas, justificando-o pelo fato de serem específicas dos seus cursos e, por isso, apresentarem maior carga horária. Mas não se inibem de criticar a ausência de oportunidades para mais trabalho de consolidação dos conteúdos suportado pelos professores, referindo, por exemplo, que "seria muito mais útil aprofundar apenas uma matéria, mas sair de lá a perceber" (2D). Tais lacunas culminam, inevitavelmente, em desconcentração, desencanto ou desmotivaçáo porque

uma pessoa não consegue pensar bem sobre as coisas. Há matérias que eu decoro para o teste e, das quais, daqui um mês, eu já náo me vou lembrar. [...] E isso desmotiva um bocado. [vários alunos concordam] Porque uma pessoa está a aprender aquilo para quê? Se uma pessoa também não consegue ver bem o que está a aprender (2B).

Esse desencanto também se percebe no próprio relacionamento entre estudantes e professores. A rigidez do ritmo de ensino invalida a possibilidade de interaçóes que tornem as relaçóes em aula menos presas ao trabalho acadêmico e mais abertas a um clima relacional positivo, como aqui se exemplifica: "nós nem tivemos apresentação nenhuma. Foi só dizer o nome de toda a gente da turma e começar a dar matéria" (2A). Como no estudo de Matos 
(2008), denota-se uma relação pedagógica professor-aluno quase exclusivamente instrumental, com um afastamento progressivo das aspiraçóes dos estudantes às expectativas profissionais de professores e político-institucionais de escolas, permeadas ainda nas dificuldades em dar qualquer sentido cognitivo às aprendizagens efetuadas que não seja aquele de permitir acesso a vias futuras (leia-se, ensino superior).

Com efeito, um ritmo de ensino menos acelerado permitiria situaçóes de ensino e aprendizagem estimuladoras de relaçóes pessoais positivas e de motivação, quer de estudantes, quer de professores. Permitiria, também, que os estudantes se sentissem mais emocionalmente apoiados, algo fulcral à integração no ensino secundário (DE WIT; KARIOJA; RYE, 2010), ultrapassando dificuldades de aprendizagem e mitigando sentimentos de pressão. Seria, ainda, muito importante para ajudar os estudantes a dar sentido aos conteúdos a aprender, tantas vezes mal consolidados, para lutar contra aquilo que Matos (2008) designou por "crise cognitiva de saberes", refletida aqui por essa estudante:

Eu tenho uma prima que está no meu curso, mas no $11^{\circ}$ ano, e eu falei-lhe da matéria do $10^{\circ}$ ano e ela falou-me para eu começar a decorar algumas coisas específicas, e eu fiquei do género "Ninguém quer saber disso! Porquê?" E ela disse-me que saiu no exame nacional, e eu fiquei chocada (2D).

São tensões entre uma cultura escolar de aprimoramento do conhecimento prescrito, de requisitos das avaliaçôes externas e da motivação intrínseca dos estudantes para a aprendizagem que emergem logo à entrada do ensino secundário e acentuam os sentimentos de pressão.

Como consequências mais individuais, surgiram referências dispersas por vários estudantes em relação a dificuldades em dormir, sentimentos de ansiedade e frustração por terem de abdicar, ou participar menos de atividades extracurriculares nas quais participavam antes (principalmente desportivas) e que, paradoxalmente, os ajudavam a lidar com a pressão e a ansiedade.

Se esses estudantes sacrificam aspetos pessoais das suas vidas, outros acabam por ter maus resultados e outros ainda optam por mudar de curso durante $\mathrm{o} 10^{\circ}$ ano, se tiverem possibilidade para tal (caso da $2 \mathrm{H}$ ). Mas há também aqueles que consideram terem se ajustado ao ensino secundário referindo estratégias de adaptação como o desenvolvimento de maior autonomia no estudo, por meio de "algum estudo por fora, até porque os próprios exercícios nos obrigam a termos de estudar antes" (2B), de maior resiliência "aplicando-me o dobro, numa disciplina que sei que não gosto" (1D) ou mais atenção e empenho nas aulas ao referir-se que "basicamente, agora, estou atento, e mesmo assim, se não perceber as coisas à primeira, tento estar ainda mais atento e colocar questôes" (2C). 
Em consonância com resultados de Gonçalves, Niemivirta e Lemos (2017), esses estudantes parecem fazê-lo movidos pelas suas metas acadêmicas pessoais que tão bem ilustram ao referirem, por exemplo, que "eu não gosto muito de algumas disciplinas. Mas trabalho nelas só porque estou a ver aquele curso [de ensino superior] à minha frente" (2B), ou que "eu só pretendo chegar à minha média, porque é só aquilo que eu quero e vai ter de ser aquilo" (2E). O cultivo de alguma responsabilidade e de motivação intrínseca é outra estratégia de adaptação, ao admitir-se que "também nos compete a nós desenvolvermos o gosto pelas disciplinas. Mesmo que nós não gostemos logo no início, temos que desenvolver o gosto pela disciplina, porque isso vai-nos facilitar depois o estudo" (1D). Para isso, e em concordância com os resultados de Diseth e Samdal (2014), jogam como fatores interrelacionados o suporte dos professores à autonomia e às motivaçóes intrínsecas dos estudantes e aos seus desempenhos acadêmicos para ultrapassarem a pressão sentida e conseguirem integrar-se no ensino secundário alcançando as suas metas. Curioso é que, quando essa pressão surge como uma dificuldade antecipada, parece ser uma estratégia protetora explicada do seguinte modo "eu não senti muita dificuldade porque eu, desde o $9^{\circ}$ ano, sempre fui avisado de que ia ser muito difícil e eu, então, comecei logo a estudar muito desde o início" (1C), o que se alinha com propostas de uma preparaçáo mais sistemática e intencional dos estudantes no ensino básico para as exigências do ensino secundário (ALCOFORADO et al., 2014; TORRES \& MOURAZ, 2015).

\section{Dificuldades acadêmicas nas vozes de estudantes em cursos profissionais}

As dificuldades acadêmicas reportadas por estudantes em cursos profissionais concentraram-se muito mais em referências à carga e distribuição horária em todos os grupos, em consonância com o também reportado pelo estudo da Direcção-Geral da Educação (DGE) (PORTUGAL, 2016b).

Estudantes das quatro escolas referiram-se a uma sobrecarga horária explicando que tinham "um horário superlotado" (2J), que "são muitas horas na escola" (1F), que "temos muitas aulas todos os dias" (4F), e que "devíamos ter um bocadinho de mais tempo livre" (3E). A distribuição horária foi também apontada pois, como bem explica essa estudante, "nós temos aulas que não precisávamos de ter tantas vezes, e há aulas que temos poucas e precisávamos de ter mais" (4G), isso porque "certas disciplinas são apenas uma vez por semana, e nós esquecemos de muitas coisas de uma semana para a outra" (4G).

Como consequências, a nível pessoal, algumas estudantes referiram o sacrifício de tempo com a família — já na adolescência, essas estudantes assumiam o apoio às tarefas domésticas - e vários outros estudantes, rapazes e moças, referiram o sacrifício de atividades como esporte e música, nas quais estariam anterior- 
mente envolvidos. Efetivamente, o ensino profissional tem uma matriz curricular onde, globalmente, os estudantes têm muito mais disciplinas e as escolas tentam encaixar tempos de formação em contexto de trabalho em um calendário escolar que ainda é dos mais compactos da Europa. E como muitos dos professores que presentemente trabalham no ensino profissional, não tiveram formação específica no modelo pedagógico modular que o caracteriza, sendo eles os próprios ex-alunos de modelos pedagógicos seletivos e aprisionados pelos saberes prescritos nos programas e ajuizados nos exames, "ainda estão agarrados aos hábitos do ensino regular [...], e mesmo o ritmo da aula vai de maneira diferente" (3E). Na perceção de alguns desses estudantes, tal como referido pelos seus colegas em cursos científico-humanísticos, esse ritmo de ensino é mais acelerado, pois "sinto que no $10^{\circ}$ ano, as professoras dão a matéria muito mais rápido. Ou somos rápidos a encaixar a matéria, ou perdemos o fio à meada" (2L) e "temos que correr ao ritmo do professor. Se esse professor anda mais um bocado, nós temos de andar ao mesmo ritmo que ele. Se não conseguimos acompanhar, fica o módulo por fazer" (4D).

A experiência do professor nos diferentes modelos pedagógicos parece ser um fator que causa alguma dificuldade nos estudantes por requerer deles a gestão de diferentes estilos de ensino quando ainda estão se habituando ao modelo pedagógico de estrutura modular que o ensino profissional preconiza. Isso está especialmente presente na perceção que os estudantes desenvolvem da estrutura modular dos cursos profissionais ao explicar, por exemplo, que "um curso profissional é mais fácil, mas é muito mais exigente em termos de repor horas. Se se falha um teste, ou tira negativa num módulo, não se avança!" (4A). Com efeito, esses estudantes refletiram visões contraditórias sobre o modelo pedagógico, reconhecendo-lhe ao mesmo tempo benefícios como "dividir as matérias e tornar-se mais fácil para nós estudar uma certa matéria naquele módulo" (2L) ou "ter sempre oportunidade de recuperar" (4D), mas também alguns obstáculos como "nunca podes ficar com um módulo por fazer!" (4A), ou "cansa mais" (2I), por sentirem que estão mais frequentemente em avaliações internas, em específico quando os módulos de diferentes disciplinas são mais curtos ou terminam em períodos próximos. De fato, tendo em conta que o modelo pedagógico modular foi identificado como um dos fatores de sucesso do ensino profissional em Portugal, ao definir "tarefas claras, sequenciais e progressivas, com metas bem identificadas, o que impede um aluno de 'cair' no insucesso administrativo" (AZEVEDO, 2014, p. 442), seria bastante importante promover uma maior coerência na implementação desse modelo em todo o ensino profissional e, em particular, no ano de transição para que a adaptação dos estudantes não encontre tantos obstáculos nessas visões contraditórias. Deve-se, contudo, salientar que as dificuldades da adaptação à carga horária e à estrutura modular parecem, simultaneamente, ser aquilo que também permite um maior apoio e proximidade da parte dos professores, uma vez que "os professores esforçam-se mais para nós entendermos. [...] têm muita mais calma a dar as coisas" (4B), sendo que possibilita também uma menor pressão para um 
estudo autônomo em casa, como se percebe na seguinte afirmação: "Num curso profissional, apesar de eu estar quase o dobro das horas na escola, em casa, eu não tenho que estudar tanto" $(1 \mathrm{H})$.

No caso concreto desses estudantes, foram referidas também dificuldades que vivenciavam com a elevada distância entre suas casas e a escola, as quais se encontram diretamente relacionadas com a elevada especialização da oferta formativa que existe atualmente nas escolas. Estudantes de três grupos distintos destacaram os longos deslocamentos que tinham de fazer diariamente e que tinham a ver com o fato de terem procurado as escolas para cursos profissionais com elevada especificidade. No caso de uma das escolas, quatro dos cinco participantes na discussão estavam em regime de internato durante a semana. A ruptura súbita com o ambiente familiar desencadeou uma responsabilização maior dos adolescentes em desenvolvimento, ampliada por uma emancipação quase forçada e restringida por alguma perda de privacidade ao terem que conviver com os seus grupos de pares dia e noite. Porventura, uma maior flexibilidade nos programas de estudos dos cursos ou o reforço de redes locais entre instituiçóes de educação e formação (FERNANDES, 2006) poderia impedir que tais estudantes tivessem que lidar com esses constrangimentos para acederem à formação que ambicionavam.

\section{Considerações finais}

As vozes de estudantes sobre as dificuldades sentidas na entrada do ensino secundário constituem um reflexo da forte divisão ainda existente entre vias acadêmicas que preparam para o ensino superior e vias profissionais que preparam para o mercado de trabalho. Estudantes em cursos científico-humanísticos lutam com a pressão do cumprir programas enraizada em políticas e práticas moldadas pela lógica da examinação e veiculada pela saturação de conteúdos, rapidez de ensino, insuficiência de reflexividade e consolidação de aprendizagens, além do aumento da exigência do trabalho autônomo, muitas vezes sem espaços de concessão das devidas ferramentas cognitivas para tal.

Já estudantes em cursos profissionais reagem de forma dupla à elevada carga horária dos seus cursos: por um lado, sentem falta de tempo fora da escola, por outro, reconhecem que isso possibilita maior proximidade e apoio dos professores e um trabalho mais consistente para a sua aprendizagem e preparação para o mercado de trabalho. Assim, apesar do estigma social que ainda permeia os cursos profissionais em Portugal, e de serem percecionados como resposta aos alunos que acumulam insucessos escolares (AZEVEDO, 2007), a transição para o ensino secundário parece configurar-se, em muitos casos, de sentimentos mais positivos para estudantes em cursos profissionais do que para estudantes em cursos científico-humanísticos. Os primeiros admitem maior ligação à escola porque "agora estamos no curso que queremos" $(2 \mathrm{H})$ e trabalham essencialmente na escola e com grande apoio dos professores. Os segundos 
revelam algum desencanto resultante da elevação brusca do ritmo, exigência e trabalho autônomo, movendo-se no ensino secundário apenas por verem nele "aquela passagem para chegar ao meu objetivo" (2B), entenda-se o ensino superior.

As alteraçóes políticas na rede escolar das últimas duas décadas terão favorecido a promoção de todas as vias de ensino secundário na lógica de alargamento da escolaridade obrigatória em Portugal e, apesar das lógicas organizacionais de escolas secundárias e escolas profissionais serem ainda diferentes, a obrigatoriedade da oferta de cursos profissionais nas escolas secundárias tem ajudado a combater a dicotomia social entre as modalidades de cursos. Mas um cenário é aquele que foi aberto pelas reformas organizacionais e outro é aquele permitido pelas reformas curriculares.

De fato, concordamos com Azevedo (2014) na ideia de que essas últimas parecem ter favorecido a "licealização" do ensino secundário geral, traduzido nos cursos científico-humanísticos. Está presente, por exemplo, no modo como os discursos de estudantes em cursos científico-humanísticos refletem o comprometimento de relaçôes positivas entre professores e alunos, táo importante para o sucesso na integração no ensino secundário (DE WIT; KARIOJA; RYE, 2010), por conta da excessividade academicista dos seus cursos. Ficou clara, nos discursos desses estudantes, a ainda persistente presença de um ensino com uma orientação pedagógica que privilegia as exigências dos saberes e dos conteúdos em detrimento das suas necessidades (MATOS, 2013).

Intervir com sucesso nessa problemática envolve uma mudança expressiva da cultura educacional vigente de preparaçáo para o ensino superior. Também a pressão que os alunos sentem é algo que mereceria maior atenção na medida em que condiciona os resultados dos alunos e o seu envolvimento na escola (PORTUGAL, 2016a). Nesse sentido, também a efetiva dotação do ensino secundário com instrumentos que operacionalizem o princípio recentemente defendido de um ensino com coerência e flexibilidade curricular (MARTINS, 2017) e ajudem a resolver o problema de transbordamento de que padece (NÓVOA, 2009), serão fatores essenciais no suporte dos professores para realmente se libertarem da "prisão" instalada daquilo "que se tem que dar"(2D). Os programas curriculares precisam de ser repensados ao nível dos seus graus de flexibilidade e de abertura, incluindo o volume de conteúdos que propóem ensinar (e, está claro, a avaliar). Precisam também de ser repensados ao nível da melhoria da articulação com o ensino básico, designadamente nas aprendizagens que os alunos precisam de desenvolver (FERNANDES, 2006) e introduzindo especializaçóes disciplinares mais progressivas.

Nada disso será eficaz, claro, sem o devido trabalho pela dotação de professores com formação e condiçóes profissionais que potenciem a sua libertação ideológica e prática da pressão dos programas, a qual muitas vezes assenta mais em uma mistura de práticas consolidadas com o uso dependente dos manuais escolares e com o culto vigente da examinaçáo, do que em políticas restritivas e 
avaliadoras. A formação deve também potenciar o trabalho colaborativo e o desenvolvimento da agência dos professores como portadores de decisão curriculares (PRIESTLEY et al., 2016) para colocar em prática um ensino mais motivador, consonante com os perfis e expectativas dos estudantes e sustentáculo do desenvolvimento da independência dos estudantes na sua própria aprendizagem.

A propósito, lembra-se que as dificuldades manifestadas pelos estudantes revelam também a enorme dicotomia entre as duas modalidades de cursos no que concerne a autonomia exigida a estudantes no seu trabalho: a uns, grande parte do trabalho é exigido fora de aulas de forma autónoma; a outros, a quase totalidade do trabalho é exigida nas aulas com monitorização dos professores. Assim, reforçamos recomendaçóes anteriores (TORRES \& MOURAZ, 2015) sobre a necessidade de se apostar mais no desenvolvimento da autonomia dos estudantes a montante do ensino secundário como forma de diminuir as dificuldades sentidas. Mas acrescentamos que, porventura, deveria promover-se a evoluçấo para uma maior convergência nos modelos pedagógicos que permeiam as duas modalidades, estimulando um trabalho mais autônomo dos estudantes em cursos profissionais, por um lado, e criando condições para um maior trabalho de proximidade e acompanhamento dos estudantes em cursos científico-humanísticos, por outro.

\section{Notas}

1. À data de submissão desse texto, estava por iniciar, em 230 escolas públicas e privadas do país, o projeto-piloto de autonomia e flexibilidade curricular (Despacho $n^{\circ}$ 5.908/2017) que, entre outros, previa a possibilidade a alunos no ano inicial do ensino secundário de trocarem algumas disciplinas da componente científica dos seus cursos, dentro de alguns limites pré-definidos e das ofertas das escolas. O projeto, entretanto alargado a todas as escolas do país que escolham aderir de forma voluntária encontra ainda, porém, várias resistências à sua implementação no ensino secundário, sobretudo pelo fato de os princípios de flexibilidade e autonomia que defende colidirem com o atual regime de acesso ao ensino superior ainda muito suportado no peso das avaliaçóes nos exames nacionais.

\section{Referências}

AKOS, P.; GALASSI, J. P. Middle and High School transitions as viewed by students, parents and teachers. Professional School Counseling, Alexandria, v. 7, p. 212-221, 2004.

ALCOFORADO, L.; PREGUIÇA, C.; URBANO, R.; GOMES, C. Escolhas escolares dos/as estudantes na transição para o ensino secundário em Portugal: reflexóes a partir do caso de uma escola de uma cidade de média dimensão. Estudos do Século XX, Coimbra, v. 14 , p. $71-91,2014$.

ANDERSON, L.; JACOBS, J.; SCHRAMM, S.; SPLITTGERBER, F. School transitions: Beginning of the end or a new beginning? International Journal of Educational Research, Amsterdã, v. 33, p. 325-339, 2000. http://dx.doi.org/10.1016/S0883-0355(00)00020-3 
ARAÚJO, H. C.; MAGALHÂES, A. M.; ROCHA, C.; MACEDO, E. Education/ social and measures regarding ESL in nine partner countries. In: REDUCING EARLY SCHOOL LEAVING IN EUROPE (RESL) (org.). Policies on Early School Leaving in Nine European Countries: A Comparative Analysis. Antwerp: University of Antwerp, 2014. p. 19-38.

ARNOT, M.; REAY, D. A Sociology of Pedagogic Voice: Power, Inequality and Pupil Consultation. Discourse, v. 28, p. 311-325, 2007. https://doi. org/10.1080/01596300701458814

AZEVEDO, J. Articulação entre níveis e ciclos de ensino. In: CONGRESSO DA SOCIEDADE PORTUGUESA DE CIÊNCIAS DA EDUCAÇÃO, 9., 2007, Funchal, Madeira. Atas [...]. Funchal, 2007.

AZEVEDO, J. O ensino profissional em Portugal, 1989-2014: viagem da periferia para o centro das políticas educativas. In: RODRIGUES, M. L. (org.). 40 anos de políticas de educaçáo em Portugal. Coimbra: Almedina, 2014. p. 411-468.

BARDIN, L. Análise de conteúdo. Lisboa: Ediçóes 70, 2000.

BENNER, A. D. The Transition to High School: Current Knowledge, Future Directions. Educational Psychology Review, Berlim, v. 23, n. 3, p. 299-328, 2011. https://dx.doi. org/10.1007\%2Fs 10648-011-9152-0

DARMODY, M. Transition to upper secondary school: An Estonian experience. Journal of Baltic Studies, Seattle, v. 39, n. 2, p. 185-208, 2008. https://dx.doi. org/10.1080/01629770802031267

DE WIT, D. J.; KARIOJA, K.; RYE, B. J. Student perceptions of diminished teacher and classmate support following the transition to high school: Are they related to declining attendance? School Effectiveness and School Improvement, Londres, v. 21, p. 451-472, 2010. https://doi.org/10.1080/09243453.2010.532010

DISETH, A.; SAMDAL, O. Autonomy support and achievement goals as predictors of perceived school performance and life satisfaction in the transition between lower and upper secondary school. Social Psychology of Education, Berlim, v. 17, n. 2, p. 269-291, 2014.

FERNANDES, D. Revisitando a revisão curricular (1997-2001): Um contributo para pensar o futuro do ensino secundário. Educaçáo. Temas e Problemas, v. 2, 129-158, 2006.

GARRIDO, J. L. Problemas do ensino secundário superior. In: AZEVEDO, J. (org.).

O Ensino Secundário em Portugal. Lisboa: Conselho Nacional de Educação, 1999. p. 229-236.

GONÇALVES, T.; NIEMIVIRTA, M.; LEMOS, M. S. Identification of students' multiple achievement and social goal profiles and analysis of their stability and adaptability. Learning and Individual Differences, Alexandria, v. 54, p. 149-159, 2017. https://doi. org/10.1016/j.lindif.2017.01.019

JENKINS, E. W. The Student Voice and School Science Education. Studies in Science Education, v. 42, p. 49-88, 2006. https://doi.org/10.1080/03057260608560220 
KRUEGER, R. A.; CASEY, M. A. Focus groups: A practical guide for applied research. 3. ed. Thousand Oaks, CA: Sage, 2000.

LOPES, M. C. Transições e pontos críticos das trajectórias de escolaridade: estudo de caso em seis escolas secundárias da Grande Lisboa. Interacçóes, Santarém, n. 1, p. 55-75, 2005.

LUNDY, L.; COOK-SATHER, A. Children's rights and student voice: their intersections and the implications for curriculum and pedagogy. In: WYSE, D.; HAYWARD, L.; PANDYA, J. (orgs.). The SAGE Handbook of Curriculum, Pedagogy and Assessment. Londres: SAGE, 2016. p. 263-277.

MARTINS, G. O. (org.). Perfil dos alunos para o século XXI - Perfil dos alunos à saída da escolaridade obrigatória (versão para consulta pública). Lisboa: Ministério da Educação, Direção Geral de Educação, 2017.

MATOS, M. Jovens, alunos, ensino secundário: um mundo crescente de contradiçôes. Educaçáo, Sociedade \& Culturas, Porto, n. 27, p. 15-26, 2008.

MATOS, M. O ensino secundário entre a "tentação neoliberal e a razão comunitária". In: MATOS, M.; CARAMELO, J. (orgs.). JOVALES, Jovens, Alunos, Ensino Secundário. Porto: CIIE/FPCEUP e Livpsic, 2013. p. 37-50.

NÓVOA, A. Professores - imagens do futuro presente. Lisboa: Educa, 2009.

OBSERVATÓRIO DE TRAJETOS DOS ESTUDANTES DO ENSINO SECUNDÁRIO (OTES). Estudantes à entrada do Secundário em 2013/2014 Portugal Continental. Lisboa: Direcção Geral de Estatísticas de Educação e Ciência (DGEEC), 2015.

OSBORNE, J.; COLLINS, S. Pupils' views of the role and value of the science curriculum: A focus-group study. International Journal of Science Education, Londres, v. 23, n. 5, p. 441-467, 2001. https://doi.org/10.1080/09500690010006518

PEREIRA, A.-J.; POOLEY, J. A. A Qualitative Exploration of the Transition Experience of Students from a High School to a Senior High School in Rural Western Australia. Australian Journal of Education, Thousand Oaks, v. 51, n. 2, p. 162-177, 2007. https:// doi.org/10.1177\%2F000494410705100205

PORTUGAL. Conselho Nacional de Educação (CNE). Estado da Educaçáo 2015. Lisboa: Conselho Nacional de Educação, 2016a.

PORTUGAL. Direção-Geral de Educação (DGE). A voz dos alunos do Secundário. In: CONFERÊNCIA CURRÍCULO PARA O SÉCULO XXI - A VOZ DOS ALUNOS, 2016. Leiria: Direção-Geral da Educação, Ministério da Educação, 2016b. Disponível em: <http://www.dge.mec.pt/sites/default/files/Curriculo/Conferencia Voz Alunos/a voz dos alunos secundario.pdf >. Acesso em: 5 maio 2017.

PRIESTLEY, M.; BIESTA, G.; PHILLIPPOU, S.; ROBINSON, S. The Teacher and the Curriculum: exploring Teacher Agency. In: WYSE, D.; HAYWARD, L.; PANDYA, J. (orgs.). The SAGE Handbook of Curriculum, Pedagogy and Assessment. Londres: SAGE, 2016. v. 1. p. 187-201. 
TEIXEIRA, C.; FLORES, M. A. Experiências escolares de alunos do ensino secundário: resultados de um estudo em curso. Educaçáo \& Sociedade, São Paulo, v. 31, n. 110, p. 113-133, 2010. http://dx.doi.org/10.1590/S0101-73302010000100007

TORRES, A. C.; MOURAZ, A. Students' transition experience in the 10th year of schooling: Perceptions that contribute to improving the quality of schools. Improving Schools, Los Angeles, v. 18, n. 2, p. 127-141, 2015. https://doi.org/10.1177\%2F1365480215581460

VAUGHAN, S.; SCHUMM, J. S.; SIAGUH, J. M. Focus Group Interviews in Education and Psychology. Londres: Sage, 1996.

VIEIRA, M. M.; PAPPÁMIKAIL, L.; NUNES, C. Escolhas escolares e modalidades de sucesso no ensino secundário: percursos e temporalidades. Sociologia, Problemas e Práticas, Lisboa, v. 70, p. 45-70, 2012. http://dx.doi.org/10.7458/SPP2012701210

Recebido em 17 de abril de 2018.

Aceito em 28 de agosto de 2018. 